\title{
Salvage transplantation for post-resection recurrence in hepatocellular carcinoma associated with hepatitis $C$ virus etiology: a feasible strategy?
}

\author{
Bhavin Bhupendra Vasavada ${ }^{1}$, Chao-Long Chan ${ }^{2}$
}

${ }^{1}$ Department of Surgical Gastroenterology, HPB Surgery and Liver Transplant, Apollo Hospital, Ahmedabad 380006, Gujarat, India ${ }^{2}$ Liver Transplant Program, Chang Gung Memorial Hospital, Taoyuan 33378, Taipei, China

\begin{abstract}
Aim: The aim was to analyze the feasibility of salvage liver transplant after liver resection in hepatocellular carcinoma (HCC) with hepatitis $\mathrm{C}$ virus (HCV) etiology. Methods: All the patients diagnosed with HCC with HCV etiology who underwent living donor liver transplant from July 2002 to November 2012 were studied. Their recurrence rate, mortality, and prognostic factors were analyzed and compared between primary transplant and salvage transplant for up to 5 years post-transplant. Results: One hundred and nine patients underwent a liver transplant for HCC associated with HCV etiology within the University of California, San Francisco criteria. Eighteen were post-hepatectomy salvage transplants and 91 were primary transplants. Median follow-up time was 31 months. One, 3 and 5 years overall survival rates were $76 \%, 76 \%$ and $65 \%$ in the salvage group, and $92 \%, 85 \%$ and $85 \%$ in primary transplant group respectively. The difference in overall survival rates was statistically significant $(P=0.031)$. However, recurrence-free survivals for 1,3 and 5 years were $72 \%, 72 \%$ and $46 \%$ for salvage group, and $91 \%, 73 \%$ and $46 \%$ for primary transplant group; which were not statistically significant $(P=0.328)$. Conclusion: Salvage transplantation for post-hepatectomy recurrence for patients with HCC associated with HCV-related chronic liver disease seems to offer inferior overall survival rates than primary transplantation.
\end{abstract}

Key words: Hepatitis C virus; hepatocellular carcinoma; salvage transplantation.

\section{Address for correspondence:}

Dr. Bhavin Bhupendra Vasavada, Department of Surgical Gastroenterology, HPB Surgery and Liver Transplant, Apollo Hospital, Ahmedabad 380006, Gujarat, India. E-mail: bhavu279@gmail.com

Received: 24-09-2014, Accepted: 23-01-2015

\section{INTRODUCTION}

Hepatocellular carcinoma (HCC) is the most common primary malignancy of the liver. ${ }^{[1]}$ There is an ongoing debate about what is the best strategy to treat HCC, particularly in Child A cirrhosis, when the primary option is resection and transplantation. Some reports have suggested that transplantation is a better choice, ${ }^{[2]}$ but the opponents of this approach suggest that resection is better because it can

\begin{tabular}{|l|c|}
\hline \multicolumn{2}{|c|}{ Access this article online } \\
\hline \multirow{2}{*}{ Website: } & Quick Response Code \\
http://www.hrjournal.net/ & \\
DOI: & \\
10.4103/2394-5079.152916 & \\
&
\end{tabular}

also serve as a bridge to liver transplantation. ${ }^{[3]}$ Many authors have suggested that results of salvage transplantation are comparable to primary transplantation. ${ }^{[4,5]}$ However, there also is controversy over management of HCC associated with hepatitis $\mathrm{C}$ virus $(\mathrm{HCV})$ related cirrhosis. Chirica et al. ${ }^{|6|}$ suggested that overall and disease-free survival after liver resection for HCV-related HCC is poor and so primary liver transplantation (LT) should be offered to these patients. In this study, we evaluated feasibility of salvage transplantation in HCC patients with HCV-related liver disease.

The aim of this study was to compare the survival rates and recurrence rates of primary as well as salvage transplantation and also to evaluate prognostic factors affecting survival and recurrence in primary as well as salvage transplantation. 


\section{METHODS}

\section{Patients selection}

All the patients transplanted for hepatitis $C$ related liver disease with HCC were analyzed retrospectively. All the data collected was at the time of liver transplant. Barcelona clinic liver cancer staging criteria were followed to decide treatment options. University of California, San Fransisco (UCSF) criteria were used as transplantation indication..$^{[7]}$ If the tumor was outside UCSF criteria, loco-regional therapies such as transarterial chemoembolization, radiofrequency ablation were used. These patients were scheduled for transplantation when they fulfilled UCSF criteria. Results with down staging are published before. ${ }^{[8]}$ Patients who underwent liver resections before and subsequently transplanted for intrahepatic recurrence were included in salvage transplant group, and other patients who were transplanted without prior resection were included in the primary transplant group. The review board of Chang Gung Memorial Hospital approved this study.

\section{Follow-up}

Patients were followed-up every 3 months for the first year, then every 6 months and yearly after that. Follow-up included liver function tests, alpha-fetoprotein (AFP) and triple-phase computed tomography scan, or magnetic resonance imaging.

\section{Statistical analysis}

Chi-square test and Fisher's $t$-test whenever appropriate were used for categorical variables and Mann-Whitney $U$-test for continues variables. Kaplan-Meier survival curves were prepared for recurrences and mortality with the Log-rank test. Multivariate analysis was performed using multivariate Cox regression analysis. SPSS version 21 (IBM, Armonk, NY, USA) was used for statistical analysis. Two-tailed significances were taken into consideration. $P<0.05$ was considered as statistically significant.

\section{RESULTS}

One hundred and nine patients underwent living donor LT for HCV-related HCC between July 2002 and November 2012. Median follow-up time was 31 months. Eighteen patients underwent salvage transplantation for intrahepatic recurrence post-hepatectomy; while 91 patients underwent primary transplants. Patients' characteristics are described in Table 1.

As described in Table 1, age of patients in both groups, mean tumor numbers and size were comparable in both the groups. The primary transplant group had statistically significant higher mean model for end-stage liver disease (MELD) score and mean Child-Turcotte-Pugh (CTP) score.

Table 1: Characteristics of 109 patients with hepatitis C virus liver disease and hepatocellular carcinoma undergoing liver transplantation as salvage or primary treatment

\begin{tabular}{|c|c|c|c|}
\hline & Salvage transplant $(n=18)$ & Primary transplant $(n=91)$ & $P$ \\
\hline Age (years, mean \pm SD) & $56 \pm 5$ & $56 \pm 6$ & 0.874 \\
\hline Sex (male, \%) & 72 & 63 & 0.471 \\
\hline MELD (mean \pm SD) & $9 \pm 4.6$ & $11 \pm 4.2$ & 0.026 \\
\hline $\mathrm{CTP}($ mean $\pm \mathrm{SD})$ & $6 \pm 1$ & $8 \pm 2$ & 0.045 \\
\hline Associated HBV infection (\%) & 28 & 15 & 0.307 \\
\hline $\begin{array}{l}\text { Pre-operative interferon and ribaverin } \\
\text { treatment (\%) }\end{array}$ & 22 & 37 & 0.283 \\
\hline Overall recurrence (\%) & 11 & 13 & 0.836 \\
\hline Pre-operative RFA (\%) & 33 & 34 & 0.971 \\
\hline Percutaneous ethanol injection (\%) & 22 & 15 & 0.433 \\
\hline Overall mortality (\%) & 28 & 12 & 0.090 \\
\hline Pre-transplant within Milan (\%) & 33 & 55 & 0.114 \\
\hline Pre-transplant TACE (\%) & 67 & 53 & 0.299 \\
\hline $\begin{array}{l}\text { Microvascular invasion on explant } \\
\text { histology (\%) }\end{array}$ & 11 & 25 & 0.178 \\
\hline $\begin{array}{l}\text { Moderate to poor differentiation on } \\
\text { explant histology (\%) }\end{array}$ & 50 & 25 & 0.052 \\
\hline Pre-operative viral load = 0 (\%) & 22 & 19 & 0.744 \\
\hline Recurrence months (mean $\pm S D$ ) & $37 \pm 32$ & $37 \pm 26$ & 0.544 \\
\hline AFP pre-operative (mean \pm SD) & $40 \pm 509$ & $123 \pm 86$ & 0.764 \\
\hline $\begin{array}{l}\text { Waiting months for transplant } \\
\text { (mean } \pm \text { SD) }\end{array}$ & $9 \pm 13$ & $9 \pm 12$ & 0.673 \\
\hline Number of tumor (mean $\pm S D$ ) & $1 \pm 2$ & $1 \pm 1$ & 0.588 \\
\hline Size of largest tumor $(\mathrm{cm}$, mean $\pm S D)$ & $2.1 \pm 1.6$ & $3 \pm 1.8$ & 0.116 \\
\hline Pre-operative viral load (mean \pm SD) & $44,153 \pm 146,079$ & $162,459 \pm 549,720$ & 0.752 \\
\hline
\end{tabular}

Data are shown as $\%$ or mean \pm SD. MELD: model for end-stage liver disease; CTP: Child-Turcotte-Pugh; HBV: hepatitis B virus; RFA: radiofrequency ablation; TACE: transarterial chemoembolization; AFP: alpha-fetoprotein; SD: standard deviation 


\section{Survival and recurrence rates comparisons in both the groups}

The two recurrences occurred in the salvage transplant group that exhibited extrahepatic metastasis. In the primary transplant group, total of 12 recurrences were noted. In two cases the recurrence was intrahepatic, and 10 were extrahepatic metastasis. One, 3 and 5 years recurrence-free survival rates were $72 \%, 72 \%$ and $46 \%$ in the salvage transplant group, and $91 \%, 73 \%$ and $46 \%$ in the primary transplant group respectively. The difference was not significant statistically $(P=0.328$ on Log-rank analysis). One-year recurrence-free survival was low in salvage transplant group, but it did not achieve statistically significant level ( $P=0.08$ for 1 year). Kaplan-Meier survival curves were shown in Figure 1. One, 3 and 5 years survival rates were $76 \%, 76 \%$ and $65 \%$ in salvage transplant group, and $92 \%, 85 \%$ and $85 \%$ in primary transplant group. Kaplan-Meier survival curves were prepared and Log-rank analysis was done [Figure 2]. One, 3 and 5 years survival rates were significantly lower in salvage transplant group $(P=0.031)$.

\section{Analysis of prognostic factors}

Prognostic factors were evaluated in all 109 patients. On the log-rank analysis, on univariate analysis high MELD score $(P=0.01)$, no pre-transplant interferon therapy $(P=0.002)$, salvage transplant, no prior transarterial chemoembolization (TACE) $(P=0.03)$ were associated with worse survival rates. On multivariate Cox regression analysis salvage transplantation $(P=0.04)$ and no pre-transplant TACE $(P=0.02)$ were independently associated with worse survival rates. Higher AFP levels were associated with worse recurrence-free survival $(P=0.005)$.

\section{DISCUSSION}

Poon et al. ${ }^{[9]}$ suggested that $80 \%$ of the intrahepatic recurrences after resection are transplantable. Based on

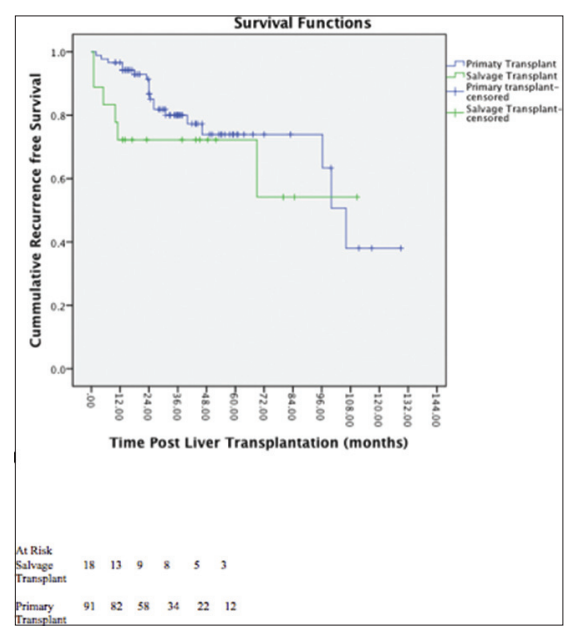

Figure 1: Recurrence free survival salvage transplant vs. primary transplant (Log rank test $P=0.328$ ) this result, many authors such as Belghiti et al. ${ }^{[10]}$ suggested that liver resection should be the first line of treatment, followed by salvage transplantation for recurrence. They also showed that 3- and 5-year survival rates were not different between primary transplantation and salvage transplantation. However, Bozorgzadeh et al..$^{[11]}$ showed that survival outcome for transplantation for HCC associated with $\mathrm{HCV}$ were significantly lower than for other etiology. Chirica et al ${ }^{[6]}$ suggested that overall and disease-free survival after liver resection for HCV-related HCC is poor and so primary LT should be offered to these patients. However Cucchetti et al. ${ }^{[12]}$ suggested good outcomes after liver resection for HCV patients.

The aim of our study was to analyze feasibility of salvage transplantation for HCC associated with HCV etiology. In this study both the salvage transplant and the primary transplant groups were comparable however the primary transplant group had significantly higher pre-operative MELD scores as well as CTP scores. MELD scores and CTP scores were not significantly associated with survival or recurrence at any step of the analysis. There were no differences with regard to pre-operative viral load and pre-operative treatment taken between two groups.

In our study, there was not statistical significant difference in recurrence-free survival between salvage transplant and primary transplant group. However, 1-, 3- and 5-year overall survival rates were significantly lower in the salvage transplant group. These results indicate that primary transplant may be a better treatment strategy for transplantable HCC in case of associated HCV etiology. Adam et $a .^{[13]}$ also showed inferior overall and recurrence-free survival in the salvage transplant group. However, they did not study HCV etiology separately. Belghiti and Durand ${ }^{[14]}$ in their editorial mentioned that in the study by Chirica

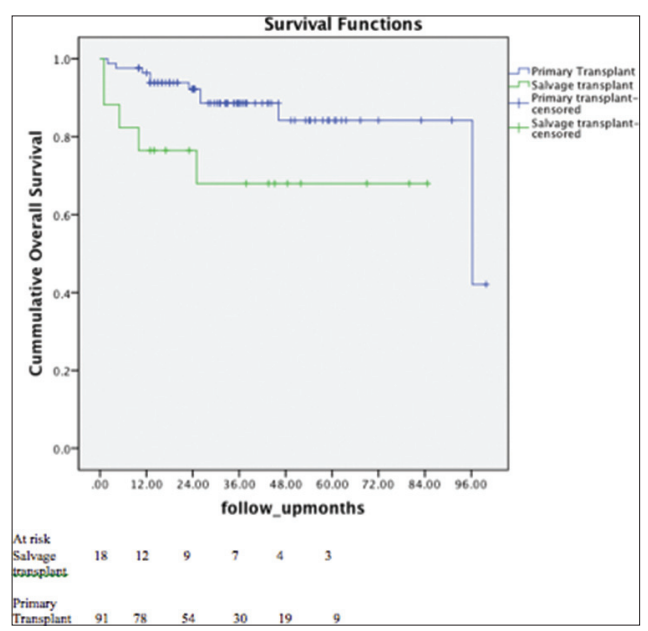

Figure 2: Overall survival in salvage transplant vs. primary transplant (Log rank test $P=0.03$ ) 
et al. ${ }^{[6]}$ tumor recurrences were outside Milan criteria after resection for $\mathrm{HCV}$ etiology so they may not be candidates for subsequent transplantation so primary transplant can be a good option for HCV-related HCC.

We also analyzed prognostic factors affecting survival and recurrence in both primary transplant and salvage transplant groups. High pre-operative AFP levels were associated with high recurrence rates. Vibert et al. ${ }^{[15]}$ also found pre-operative AFP as a significant prognostic factor for poor survival and recurrence. High MELD score, no pre-transplant interferon therapy, salvage transplant and no prior transarteral chemoembolization was associated with worse survival rates. In multivariate Cox regression, analysis salvage transplant and no prior transcatheter arterial chemoembolization were independent predictors of worse outcome. Shimoda et al. ${ }^{[16]}$ suggested that advanced tumor stage and particularly vascular invasion are poor prognostic indicators for tumor recurrence. The authors showed that early pathological tumor-node-metastasis stage, adjuvant chemotherapy, and pre-operative chemoembolization were associated with better outcomes for LT for concomitant HCV and HCC. In our studies, however, factors like vascular invasion, tumor number, tumor size, and presence of vascular invasion, tumor differentiation or histological grade did not achieve statistical significance. HCV viral load did not achieve statistical significance in predicting neither recurrence nor survival $(P=0.8$ and 0.9 respectively). Pre-operative MELD and CTP scores were significantly higher in the primary transplant group but still these patients achieved better survival rates than the salvage transplant group. Even in advanced underlying disease cases, primary transplant achieved best results. Patients in the salvage transplants had mean CTP of 6 , indicating that the majority of them had a compensated, or Child A cirrhosis and their survival was lower than the primary transplant group. There was no statistical difference between recurrence-free survival between primary and salvage transplant group, however 1 year recurrence free survival was $72 \%$ in case of salvage transplant and $91 \%$ in primary transplant with $P<0.1$ (though not $<0.05$ ), and most of the death were due to HCV and HCC recurrences. One death was due to post-operative bleeding as salvage transplant is technically more difficult than primary transplant. Pre-operative sustained virological response and pre-operative viral load was less in salvage transplant group though non-significant.

In the era of new and more efficacious anti-HCV drugs, this survival difference will be probably overcome. Thus, patients with HCC and HCV can receive salvage LT but probably they should receive pre-emptive antiviral therapy.
There are certain limitations of this study as this are a retrospective analysis. We also recognize that the numbers of patients in the salvage transplantation group were relatively low and with just two recurrences in salvage transplant group, statistical significance of the recurrence rate is weak. Another limitation is that we did not have complete pathological details of prior liver resection specimens in salvage transplant group as some of them were referred to us after resection; in addition, some patients underwent resection before 2002, and complete pathological analysis was not available.

In conclusion transplantation for post-hepatectomy recurrence for patients with HCC associated with HCV-related chronic liver disease seems to offer inferior overall survival rates than primary transplantation. However, results in the era of new anti-HCV drugs need to be evaluated further.

\section{REFERENCES}

1. Rustgi VK. Epidemiology of hepatocellular carcinoma. Gastroenterol Clin North Am 1987;16:545-51.

2. Bigourdan JM, Jaeck D, Meyer N, Meyer C, Oussoultzoglou E, Bachellier P, Weber JC, Audet M, Doffoël M, Wolf P. Small hepatocellular carcinoma in Child A cirrhotic patients: Hepatic resection versus transplantation. Liver Transpl 2003;9:513-20.

3. Facciuto ME, Rochon C, Pandey M, Rodriguez-Davalos M, Samaniego S, Wolf DC, Kim-Schluger L, Rozenblit G, Sheiner PA. Surgical dilemma: Liver resection or liver transplantation for hepatocellular carcinoma and cirrhosis. Intention-to-treat analysis in patients within and outwith Milan criteria. HPB (Oxford) 2009;11:398-404.

4. Vennarecci G, Ettorre GM, Antonini M, Santoro R, Maritti M, Tacconi G, Spoletini D, Tessitore L, Perracchio L, Visco G, Puoti C, Santoro E. First-line liver resection and salvage liver transplantation are increasing therapeutic strategies for patients with hepatocellular carcinoma and Child A cirrhosis. Transplant Proc 2007;39:1857-60.

5. Hu Z, Wang W, Li Z, Ye S, Zheng SS. Recipient outcomes of salvage liver transplantation versus primary liver transplantation: A systematic review and meta-analysis. Liver Transpl 2012;18:1316-23.

6. Chirica M, Tranchart H, Tan V, Faron M, Balladur P, Paye F. Infection with hepatitis $\mathrm{C}$ virus is an adverse prognostic factor after liver resection for early-stage hepatocellular carcinoma: Implications for the management of hepatocellular carcinoma eligible for liver transplantation. Ann Surg Oncol 2013;20:2405-12.

7. Yao FY, Ferrell L, Bass NM, Watson JJ, Bacchetti P, Venook A, Ascher NL, Roberts JP. Liver transplantation for hepatocellular carcinoma: Expansion of the tumor size limits does not adversely impact survival. Hepatology 2001;33:1394-403.

8. Yu CY, Ou HY, Huang TL, Chen TY, Tsang LL, Chen CL, Cheng YF. Hepatocellular carcinoma downstaging in liver transplantation. Transplant Proc 2012;44:412-4.

9. Poon RT, Fan ST, Lo CM, Liu CL, Wong J. Long-term survival and pattern of recurrence after resection of small hepatocellular carcinoma in patients with preserved liver function: Implications for a strategy of salvage transplantation. Ann Surg 2002;235:373-82.

10. Belghiti J, Cortes A, Abdalla EK, Régimbeau JM, Prakash K, Durand F, Sommacale D, Dondero F, Lesurtel M, Sauvanet A, Farges O, Kianmanesh R. Resection prior to liver transplantation for hepatocellular carcinoma. Ann Surg 2003;238:885-92. 
11. Bozorgzadeh A, Orloff M, Abt P, Tsoulfas G, Younan D, Kashyap R, Jain A, Mantry P, Maliakkal B, Khorana A, Schwartz S. Survival outcomes in liver transplantation for hepatocellular carcinoma, comparing impact of hepatitis $\mathrm{C}$ versus other etiology of cirrhosis. Liver Transpl 2007;13:807-13.

12. Cucchetti A, Cescon M, Ercolani G, Morelli MC, Del Gaudio M, Zanello M, Pinna AD. Comparison between observed survival after resection of transplantable hepatocellular carcinoma and predicted survival after listing through a Markov model simulation. Transpl Int 2011;24:787-96.

13. Adam R, Azoulay D, Castaing D, Eshkenazy R, Pascal G, Hashizume K, Samuel D, Bismuth H. Liver resection as a bridge to transplantation for hepatocellular carcinoma on cirrhosis: a reasonable strategy? Ann Surg 2003;238:508-18.

14. Belghiti J, Durand F. Hepatectomy vs. liver transplantation: a combination rather than an opposition. Liver Transpl 2007;13:636-8.
15. Vibert E, Azoulay D, Hoti E, Iacopinelli S, Samuel D, Salloum C, Lemoine A, Bismuth H, Castaing D, Adam R. Progression of alphafetoprotein before liver transplantation for hepatocellular carcinoma in cirrhotic patients: a critical factor. Am J Transplant 2010;10:129-37.

16. Shimoda M, Ghobrial RM, Carmody IC, Anselmo DM, Farmer DG, Yersiz H, Chen P, Dawson S, Durazo F, Han S, Goldstein LI, Saab S, Hiatt J, Busuttil RW. Predictors of survival after liver transplantation for hepatocellular carcinoma associated with Hepatitis C. Liver Transpl 2004;10:1478-86.

How to cite this article: Vasavada BB, Chan CL. Salvage transplantation for post-resection recurrence in hepatocellular carcinoma associated with hepatitis C virus etiology: a feasible strategy? Hepatoma Res 2015;1:36-40.

Source of Support: Nil. Conflict of Interest: None declared. 